Histology, Cytology and Embryology (HCE)

\title{
Antioxidant properties of Mentha pulegium and histopathological evaluation of its ameliorating effect on experimental acute hepatic injury
}

\author{
Ismail H. Osman ${ }^{* 1,2}$, Ahmed A. Tantawy ${ }^{1,3}$, Hussein M. Ibrahim ${ }^{1,4}$, and Abd El Ghany A. Moustafa ${ }^{1,5}$ \\ ${ }^{1}$ College of Applied Medical Sciences, Aljouf University, Saudi Arabia \\ ${ }^{2}$ College of Medicine, Bahri University, Sudan \\ ${ }^{3}$ Pathology Department, Faculty of Veterinary Medicine, Benha University, Egypt \\ ${ }^{4}$ Department of Anatomy and Embryology, Faculty of Medicine, Ain Shams University, Cairo, Egypt \\ ${ }^{5}$ Histology Department, Faculty of Medicine, Al-Azhar University, Damietta, Egypt
}

\begin{abstract}
The current study was designed to evaluate antioxidant properties and hepatoprotective effect of Mentha pulegium ( $M$. pulegium). Antioxidant activity of ethanol $M$. pulegium extract was evaluated by 1,1-diphenyl-2-picrylbydrazyl (DPPH) free radical scavenging assay and its ability to inhibit lipid peroxidation was estimated by using liposome oxidation system. Total phenol and flavonoid contents were measured by folin-ciocalteau assay and $\mathrm{AlCl}_{3}$ method respectively. $M$. pulegium extract effectively inhibited lipid peroxidation but it was less effective against DPPH free radicals. The possible hepatoprotective effect of $M$. pulegium extract was evaluated histopathologically and imunohistochemically. Hepatotoxicity was induced by single subcutaneous injection of $\mathrm{CCl}_{4}$ at a dose of $0.75 \mathrm{ml} / \mathrm{kg}$ body weight. $\mathrm{Massive}$ hepatic damage in the form of hepatocellular degeneration, apoptosis and necrosis with marked immunoexpression of caspase-3 and iNOS were recorded in the examined liver after $\mathrm{CCl}_{4}$ injection. Oral pre-administration of $M$. pulegium extract for 8 successive days to $\mathrm{CCl}_{4}$ intoxicated rabbits, revealed significant improvement in the microscopic pictures of the examined liver with significant decrease immunoexpression of caspase- 3 and iNOS compared with those of $\mathrm{CCl}_{4}$ intoxicated group. The present study suggested that $M$. pulegium possess antioxidant activity that could protect hepatocytes against acute hepatic damage and its protective effect probably dose-dependent.
\end{abstract}

\section{Introduction}

Although liver disease is typically linked to alcohol or drugs, but there are over 100 known forms of liver diseases all over the world caused by a variety of causes affecting human being from infants to older adults. In Kingdom of Saudi Arabia, hepatic disorders constitute an important common health problem usually associated with significant mortality and morbidity rates $[1,2]$. These disorders include mostly hepatitis $\mathrm{B}$ and $\mathrm{C}$, in addition to other causes such as autoimmune hepatitis, Wilson's disease and non-alcoholic steatohepatitis [3]. Treatment of liver failure remains one of the main critical problems in clinical medicine and current drug therapy for management of liver diseases causes adverse side effects [4].

Medicinal plants help as potential source of useful recent compounds for the development of effective therapy to combat hepatic disorders. It's well established that antioxidants are effective in preventing or suppressing many diseases. Therefore, there is great attention in finding antioxidants of plant origin that might help in preventing or decreasing oxidative damages with minimal side effects [5]. Worldwide there are about 25-30 Mentha species [6]. M. pulegium is the most common species of Mentha in Saudi Arabia, known as AlMedina mint and usually added in commercial spice mixtures and herbal tea [7]. In addition, Mentha species has been used as a folk remedy for treatment of nausea, bronchitis, anorexia, ulcerative colitis, and liver diseases [8]. Several studies have examined the antioxidant activity of Mentha species growing in various regions of the world
$[9,10]$. However, there are no detailed reports on hepatoprotective effects of M. pulegium growing in Saudi Arabia.

The aim of the present study was to investigate in vitro antioxidant properties and the hepatoprotective effect of $M$. pulegium extract against experimentally induced hepatic damage in animal model.

\section{Materials and methods}

\section{Chemicals and materials}

2,2,-diphenyl-1-picrylhydrazyl, gallic acid, Folin-Ciocalteu reagent, ascorbic acid, trichloro-acetic acid, sodium nitrite, aluminum chloride, phosphatidylcholine, thiobarbituric acid, hydrochloric acid and carbon tetrachloride were obtained from Sigma Chemical Co. (St Louis, MO, USA). Anti-caspase- 3 antibodies and Horseradish peroxidase labeled secondary antibodies obtained from Thermo Fisher Scientific Co. (Waltham, MA, USA). Fresh leaves of M. pulegium were purchased from local markets in Madinah EL Monawara, KSA, washed, air dried

Correspondence to: Ismail Hamad, College of Applied Medical Sciences, Aljouf University, Saudi Arabia, E-mail: ihosman@ju.edu.sa

Key words: Mentha pulegium, histopathology, caspase-3, iNOS, acute liver damage, antioxidant

Received: December 03 , 2016; Accepted: January 18, 2017; Published: January 21,2017 
and kept frozen at $-20^{\circ} \mathrm{C}$ until used.

\section{Extract preparation}

Ultrasound-assisted emulsification-micro extraction method was used for extraction of total phenol and flavonoid compounds [11]. Briefly 30 grams of dried leaves and $60 \mathrm{ml}$ of $\mathrm{n}$-hexane were mixed.2.5 $\mathrm{ml}$ of $20 \%$ ethanol was added. After shaking for few seconds, the mixture was placed in ultrasonic water bath $(40 \mathrm{kHz}$ of ultrasound frequency and $130 \mathrm{~W}$ of power for $15 \mathrm{~min}$ at $25^{\circ} \mathrm{C}$ ), then centrifuged at $9000 \mathrm{~g}$ for $15 \mathrm{~min}$. The extraction solvent was collected and concentrated using rotary evaporator then the dried extract was kept frozen at $-20^{\circ} \mathrm{C}$

\section{Estimation of total phenol and flavonoid contents}

Total phenol content (TPC) of the ethanol extract of M. pulegium was estimated by using Folin-Ciocalteu reagent. Gallic acid was used as a standard. The total phenolic content was expressed as mg gallic acid equivalents (GAE)/g dry weight of extract (DWE) [12]. Total flavonoid content (TFC) was determined colorimetrically according to the method of Eberhardt et al. [13]. Rutin was used as a standard. The total flavonoid content was expressed as mg Rutin equivalents (RTE)/g dry weight of extract (DWE).

\section{DPPH free radical scavenging assay}

DPPH free radical scavenging activity of extract was estimated as described previously [14]. Briefly, $160 \mu \mathrm{L}$ of $0.2 \mathrm{mM} \mathrm{DPPH}$ in ethanol were mixed with $40 \mu \mathrm{L}$ of each extract $(0.01-1 \mathrm{mg} / \mathrm{mL})$ in 96 microplates. Ascorbic acid was used as a reference compound.

\section{Anti-lipid peroxidation assay}

Lipid peroxidation was carried out as described in previous study [15]. Briefly, $300 \mathrm{mg}$ phosphatidylcholine in $30 \mathrm{~mL} 10 \mathrm{mM}$ phosphate buffer at $\mathrm{pH} 7.4$ were sonicated on ice for 2 hours to form small micelles. To a total volume $(1 \mathrm{ml})$ containing potassium phosphate buffer at $\mathrm{pH} 7.4(10 \mathrm{mM})$, the liposome $(250 \mu \mathrm{l})$, and extract or extraction solvent $(450 \mu \mathrm{l})$, was added to $\mathrm{FeCl}_{2}, \mathrm{H}_{2} \mathrm{O}_{2}$ and ascorbic acid each in a final concentration of $125 \mu \mathrm{M}$. After incubating the mixture at $30^{\circ} \mathrm{C}$ for $4 \mathrm{~h}, 250 \mu \mathrm{l}$ of the final mixture was added to $500 \mu \mathrm{l} \mathrm{TCA}-\mathrm{TBA}-\mathrm{HCL}$ reagent $(15 \% w / v$, TCA; $0.375 \% w / v$, TBA; $0.25 \mathrm{M} \mathrm{HCL})$ and heated at $100^{\circ} \mathrm{C}$ on a boiling water bath for $15 \mathrm{~min}$. After centrifugation at $3,000 \mathrm{~g}$ for $5 \mathrm{~min}$. The absorbance was monitored at $532 \mathrm{~nm}$ against blank. Trolox was used as a reference antioxidant.

\section{Evaluation of hepatoprotective effect of M. pulegium}

\section{Animals}

Adult male rabbits weighing 1.25 to $2.0 \mathrm{~kg}$ were housed individually in stainless steel wire cages with controlled environment at $21 \pm 2^{\circ} \mathrm{C}$, and relative humidity at $50 \pm 5$ under a $12 \mathrm{~h}$. dark/light cycle for one week of acclimatization. Animals were fed rabbit's standard ration and allowed free access to tap water. All the experimental procedures were carried out in agreement with the Ethics Committee of Aljouf University, Saudi Arabia.

\section{Experimental design}

Twenty five adult male rabbits were divided into 5 equal groups. In first group (control), rabbits were subcutaneously injected with olive oil (vehicle) on $8^{\text {th }}$ day. In second group, rabbits received orally silymarin $100 \mathrm{mg} / \mathrm{kg} /$ day. In third group, rabbits were given orally M. pulegium extract $100 \mathrm{mg} / \mathrm{kg} /$ day and in fourth group, rabbits were given orally M. pulegium extract $50 \mathrm{mg} / \mathrm{kg} /$ day. At $8^{\text {th }}$ day, animals of second, third, fourth and fifth group ( $\mathrm{CCL}_{4}$ intoxicated group), were injected subcutaneously with $\mathrm{CCl}_{4}$ (suspended in olive oil at $1: 1$ ) at a dose of $0.75 \mathrm{ml} / \mathrm{kg}$ body weight. Twenty-four hours post- administration of $\mathrm{CCl}_{4}$, rabbits in all groups were sacrificed.

\section{Histopathological study}

Small liver tissue specimens were collected from rabbits in all groups and immediately fixed in $10 \%$ neutral buffered formalin. After proper fixation, $5 \mu \mathrm{m}$ tissue paraffin sections were routinely prepared and stained with H\&E stain for light microscopic examination [16].

\section{Immunohistochemical study}

Immunohistochemistry of Caspase- 3 and iNOS were carried out as described by Laurentino et al., [17]. Briefly, $5 \mu \mathrm{m}$ tissue paraffin sections of the liver were deparaffinized in xylene, rehydrated in a graded-alcohol series, and treated with $3 \%$ hydrogen peroxide for $10 \mathrm{~min}$. The sections were subsequently washed in PBS and incubated 10 minutes at $22^{\circ} \mathrm{C}$ with $10 \%$ goat serum to block unspecific binding. Then sections were incubated overnight at $4^{\circ} \mathrm{C}$ with the specific rabbit's primary antibody for iNOS and anti-caspase- 3 antibodies diluted in PBS. Thereafter, the sections were washed twice in PBS for 5 min each. Horseradish peroxidase labeled secondary antibodies were applied and the sections were again incubated for $20 \mathrm{~min}$, followed by washing 3 times in PBS for 5 min each. Di-amino-benzidine tetrahydrochloride solution was applied to the sections and further incubation for $10 \mathrm{~min}$ was done. The sections were washed in distilled water and counterstained with hematoxylin.

These sections were examined using Olympus DP2-BSW Image computer system (Olympus Imaging System., Tokyo, Japan), and Image Pro Plus program (version 4.5.1.27) was used to achieve morphometric data. Five non overlapping fields in slides of each animal of each group were examined for quantitative morphometric measurement of the mean of optical density and area percentage of caspase 3 and iNOS reaction at magnification of $400 \mathrm{x}$.

\section{Statistical analysis}

SPSS 20.0 statistical package was used to perform all statistical analyses. one-way analysis of variance (ANOVA) followed by Tukey's test was used for comparing control and treated groups. The results were expressed as mean \pm SD. A probability $(\mathrm{P})$ level of $\leq 0.05$ was considered statistically significant.

\section{Results}

Total phenol, flavonoid contents and antioxidant activity of M. pulegium

Total phenol compounds, total flavonoids, DPPH scavenging activity and anti-lipid peroxidation of $M$. pulegium ethanol extract were estimated spectrophotometrically. As shown in Table 1, total phenol and flavonoid contents of $M$. pulegium extract were $12.34 \pm$ $0.74 \mathrm{mg} / \mathrm{g}$ gallic acid equivalent and $2.11 \pm 0.011 \mathrm{mg} / \mathrm{g}$ rutin equivalent,

Table 1. Total phenol, flavonoid contents and antioxidant activity $(\mathrm{EC} 50, \mu \mathrm{g} / \mathrm{mL})$ of the Mentha ethanol extract.

\begin{tabular}{|l|c|c|c|c|}
\hline & $\begin{array}{c}\text { Total phenols } \\
(\mathbf{m g ~ G A E} / \mathbf{g} \text { DWE) }\end{array}$ & $\begin{array}{c}\text { Total flavonoids } \\
(\mathbf{m g} \text { CATE/g DWE) }\end{array}$ & $\begin{array}{c}\text { DPPH } \\
\mathbf{E C}_{\mathbf{5 0}}, \boldsymbol{\mu g} / \mathbf{m L}\end{array}$ & $\begin{array}{c}\text { TBARS } \\
\mathbf{E C}_{\mathbf{5 0}}, \boldsymbol{\mu g} / \mathbf{m L}\end{array}$ \\
\hline $\begin{array}{l}\text { M. pulegium } \\
\text { extract }\end{array}$ & $12.34 \pm 0.74 \mathrm{mg}$ & $2.11 \pm 0.011 \mathrm{mg}$ & $1687.67 \pm$ & $125 \pm 1.22$ \\
\hline Vitamin C & - & - & $42.06 \pm 2.40$ & - \\
\hline Trolox & - & - & - & $12.54 \pm 0.13$ \\
\hline
\end{tabular}


respectively. In the $\mathrm{DPPH}$ scavenging assay, $\mathrm{EC}_{50}$ values of $M$. pulegium was $1687.67 \pm 2.026 \mu \mathrm{g} / \mathrm{mL}$ In the TBARS assay, $\mathrm{EC}_{50}$ values of $M$. pulegium was $125 \pm 1.22 \mu \mathrm{g} / \mathrm{mL}$.

\section{Histopathological findings}

Microscopically, the examined liver of rabbits in first control group showed normal structure of the liver with distinct hepatocytes and sinusoidal spaces (Figure 1-A). In contrast, the histopathological examination of the liver of rabbits in fifth $\left(\mathrm{CCl}_{4}\right.$ intoxicated) group revealed congestion of central veins with severe hepatocellular damage represented by diffuse macrovesicular and microvesicular steatosis and ballooning degeneration of hepatocytes including centrilobular, midzonal and periportal areas with apoptosis of hepatocytes (Figure 1-B). The apoptotic hepatocytes showed hypereosinophilic cytoplasm and fragmented nuclear material within the cytoplasm (Figure 1-C). Some of these cells were surrounded by a clear halo due to contraction of the apoptotic hepatocytes (Figure 1-D). In addition, focal areas of hepatic necrosis were also coexisted with apoptosis of hepatic cells. Multiple mononuclear inflammatory cellular infiltration of hepatic parenchyma particularly lymphocytes were seen. Moreover, the examined portal areas showed bile ductal hyperplasia with degeneration of their lining epithelium (Figure 1-E). The microscopic examination of liver of rabbits in second group (silymarin $+\mathrm{CCl}_{4}$ ) revealed only mild hepatic lesions in the form of vacuolar, hydropic and ballooning degeneration of some hepatic cells (Figure 2-A). Also, the examined liver of rabbits in third group (100 mg mentha $\left.+\mathrm{CCl}_{4}\right)$ showed significant improvement in the microscopic pictures compared with those of $\mathrm{CCl}_{4}$ induced hepatotoxicity group where mild hepatic damage characterized by hydropic and ballooning degeneration of some hepatocytes in centrilobular areas with focal mononuclear inflamatory cellular aggregation among hepatic parenchyma was seen (Figure

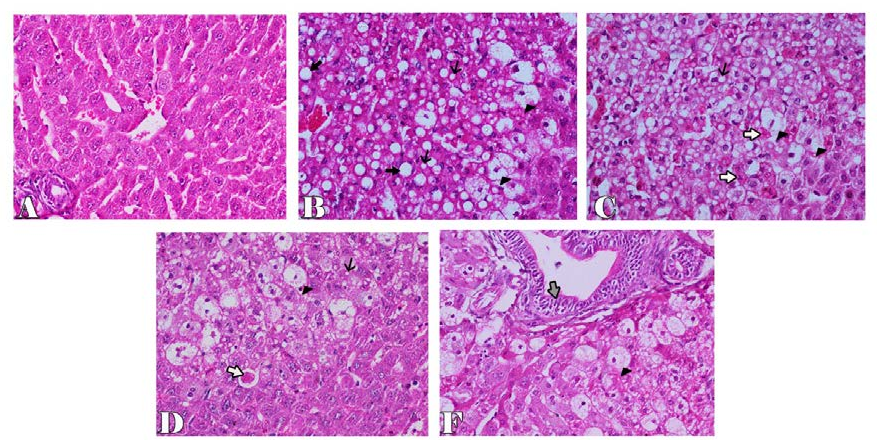

Figure 1. Liver of rabbit in control group showing normal histological structure of the liver with distinct hepatocytes and sinusoidal spaces (A), in $\mathrm{CCl}_{4}$ intoxicated group showing microvesicular and macrovesicular hepatic steatosis (thin and thick arrows) with ballooning degeneration of hepatocytes (arrowhead) (B), apoptosis of hepatic cells (white arrows) (C), clear halo surrounded apoptotic cell (white arrow) (D), bile ductal hyperplasia and degeneration of their lining epithelium (gray arrow) (F). H \& E stain X200.
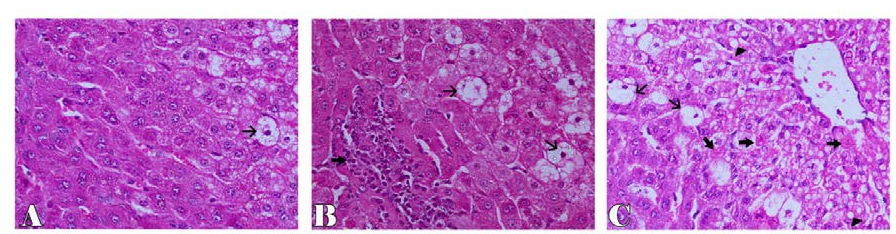

Figure 2. Liver of rabbit showing ballooning degeneration of few hepatic cells (thin arrow) in $\mathrm{CCl}_{4}+$ silymarin group (A), focal mononuclear inflammatory cells aggregation (thick arrow) and ballooning degeneration of some hepatocytes (thin arrow) in $\mathrm{CCl}+100$ mentha group (B), ballooning (thin arrows), fatty degeneration (arrow head) and apoptosis of hepatocytes (thick arrows) in $\mathrm{CCl}_{4}+50$ mentha group (C). H\&E stain X200.
2-B). In fourth group, pretreatment with $50 \mathrm{mg}$ mentha was also associated with improvement of liver microscopic picture, where the hepatic damage was restricted to centrilobular areas and characterized by hepatic steatosis and ballooning degeneration of hepatocytes with apoptosis of individual scattered hepatocytes (Figure 2-C).

\section{Immunohistochemistry of caspase- 3 and iNOS}

For immunohistochemical study, iNOS was used to detect oxidative damage, and caspase- 3 was used for detection of apoptosis in hepatic cells. In the control group, the hepatocytes showed weak or no caspase and iNOS immunoreactivity (Figures $3 \mathrm{~A}$ and $4 \mathrm{~A}$ ). The expression of caspase- 3 and iNOS were increased upon $\mathrm{CCl}_{4}$ injection indicating that hepatocytes exhibited an increase in apoptosis and oxidative stress respectively (Figures $3 \mathrm{~B}$ and $4 \mathrm{~B}$ ). Liver sections of rabbits treated with $100 \mathrm{mg}$ silymarin (Figures 3C and 4C), $100 \mathrm{mg}$ Mentha (Figures 3D and $4 \mathrm{D}$ ) and $50 \mathrm{mg}$ Mentha extract (Figures 3E and 4E) showed weak expression of caspase- 3 and iNOS.

Morphometric analysis revealed a significant increase in the mean optical density and area percentage of caspase 3 and iNOS immunoreactivity in the $\mathrm{CCl}_{4}$ intoxicated rabbits in comparison with control group. In addition, liver sections of rabbits pretreated with $100 \mathrm{mg}$ silymarin, $100 \mathrm{mg}$ Mentha and $50 \mathrm{mg}$ Mentha extract showed significant reduction in the mean of optical density and area percentage of caspase 3 and iNOS immunoreactivity when compared with the CCl treated group. Moreover, in $\mathrm{CCl}_{4}+100 \mathrm{mg}$ mentha extract group the values of morphometric data of caspase-3 and iNOS expression were

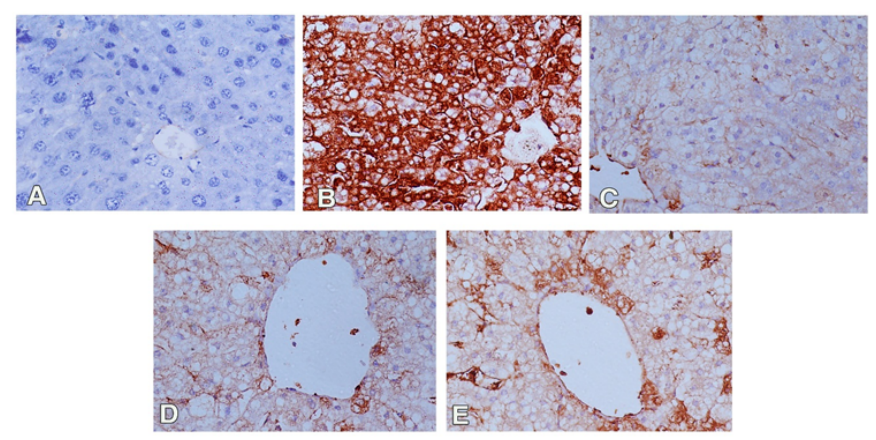

Figure 3. Immunostained liver sections for caspase-3 showing no expression of caspase-3 in control group(A); marked expression of caspase-3 in $\mathrm{CCL}_{4}$ intoxicated group (B); weak expression of caspase-3in pretreated groups with silymarin (C), $100 \mathrm{mg}$ Mentha (D) and 50 mg Mentha extract (E). (400X)

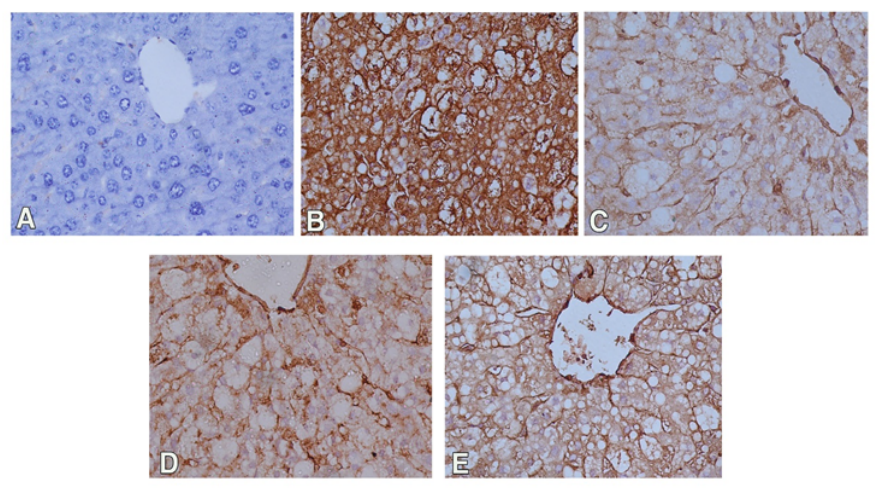

Figure 4. Immunostained liver sections for iNOS showing no expression of iNOS in control group (A); marked expression of iNOS in $\mathrm{CCL}_{4}$ intoxicated group (B); weak expression of iNOS in pretreated groups with silymarin (C), $100 \mathrm{mg}$ Mentha (D) and 50mg Mentha extract (E). (400X). 
Table 2. The optical density (OD) and the area percentage (A\%) of caspase-3 and iNOS expression.

\begin{tabular}{|c|c|c|c|c|}
\hline Groups & Caspase3 (OD) & Caspase-3(A\%) & iNOS (OD) & iNOS(A\%) \\
\hline Control & $0.061 \pm 0.028$ & $0.390 \pm 0.215$ & $0.073 \pm 0.017$ & $1.743 \pm 1.400$ \\
\hline $\mathrm{CCl}_{4}$ & $0.624 \pm 0.031^{*}$ & $46.720 \pm 3.864^{*}$ & $0.449 \pm 0.056^{*}$ & $54.578 \pm 3.890^{*}$ \\
\hline $\mathrm{CCl}_{4}+$ Silymarin & $0.108 \pm 0.006^{* *}$ & $1.464 \pm 0.658^{* *}$ & $0.110 \pm 0.011 * *$ & $7.841 \pm 1.069 * *$ \\
\hline $\mathrm{CCl}_{4}+M$. pulegium $(100 \mathrm{mg} /$ day $)$ & $0.146 \pm 0.025^{* *}$ & $6.288 \pm 1.378^{* *}$ & $0.226 \pm 0.019^{* *}$ & $18.415 \pm 3.258^{* *}$ \\
\hline $\mathrm{CCl}_{4}+$ M. pulegium $(50 \mathrm{mg} /$ day $)$ & $0.201 \pm 0.019 * *$ & $17.390 \pm 3.405^{* *}$ & $0.320 \pm 0.018^{* *}$ & $25.638 \pm 2.476^{* *}$ \\
\hline
\end{tabular}

greatly reduced than those recorded in $\mathrm{CCl}_{4}+50 \mathrm{mg}$ mentha extract group (Table 2).

\section{Discussion}

Oxidative stress has been considered as a common pathological mechanism contributes to initiation and progression of liver damage. There were different risk factors including alcohol, drugs, environmental pollutants and irradiation induce oxidative stress in hepatic cells leading to severe hepatic disorders [18]. Over years, researches were carried out on application of natural antioxidants to prevent and treat liver diseases involving oxidative stress. Several animal studies revealed the promising protective effects of plant extracts that contained natural antioxidants on hepatic damage $[4,15]$.

The antioxidant properties of plant extracts depends on its capability to act as radical scavenger, hydrogen donor or reducing agent according to their total phenol and flavonoid contents [19]. In the present study, the total phenol content (TPC) and total flavonoid content (TFC) of M. pulegium were $12.34 \pm 0.74 \mathrm{mg} \mathrm{GAE} / \mathrm{g}$ DWE and $2.11 \pm 0.011 \mathrm{mg} \mathrm{RTE} / \mathrm{g}$ DWE respectively. The TPC of ethanol extract of Saudi M. pulegium was higher than those found in Algerian $M$. pulegium methanol extract where TPC was $6.1 \pm 0.5 \mathrm{mg} \mathrm{GAE} / \mathrm{g}$ DWE [20]. However, in other study, level of TPC of Turkish M. pulegium methanol extract was greatly higher up to $206.58 \pm 4.54 \mathrm{mg} \mathrm{GAE} /$ g DWE [10,21]. These variations in TPC in M. pulegium between countries could be attributed to differences in geographical locations, climatic conditions, season at the time of collection and methods of extraction.

$\mathrm{CCl}_{4}$ is known as a potent hepatotoxic agent that commonly used to study the hepatotoxicity in experimental animals for evaluation of hepatoprotective agents $[22,23]$. In the present study, hepatotoxicity was induced by single subcutaneous injection of $\mathrm{CCl}_{4}$ in rabbit model. This hepatotoxicity was microscopically characterized by severe hepatocellular damage represented by massive degeneration and apoptosis of hepatocytes in addition to mononuclear cellular infiltration of the hepatic necrotic areas. This hepatic damage induced by $\mathrm{CCl}_{4}$ in the present investigation could be attributed to generation of reactive oxygen species in hepatic tissues and decreased activities of antioxidant enzymes caused by $\mathrm{CCl}_{4}$ [24]. In a previous study, similar microscopic hepatic lesions were also recorded in liver of rats intoxicated with $\mathrm{CCl}_{4}$ [23].

In addition, the liver of rabbits intoxicated with $\mathrm{CCl}_{4}$ exhibited a significant iNOS and caspase 3 expression. These results indicated that $\mathrm{CCl}_{4}$ induced severe hepatic changes through enhancement of oxidative stress and induction of apoptosis. This opinion was supported by Weber et al., and Zhang et al., reported that $\mathrm{CCl}_{4}$ induces severe apoptosis in hepatocytes due to its toxin-induced excessive oxidative stress, depletion of antioxidant enzymes and induction of membrane lipid peroxidation which may prompt the extrinsic or intrinsic apoptotic pathways [25,26]. Moreover, Guicciardi and Gores added that, these apoptotic pathways finally lead to activation of caspases pathway for apoptosis that ends up with caspase- 3 activation, real apoptosis executioner and once generated, the active caspases initiates cell apoptosis [27]. In addition, TNF- $\alpha$ is a proinflammatory mediator commonly rises following exposure to hepatotoxic chemicals as $\mathrm{CCl}_{4}$. TNF- $\alpha$ induces iNOS and stimulates production of nitric oxide (NO), contributing to nitrosative stress. NO may react with superoxide $\left(\mathrm{O}^{2-}\right)$ in the mitochondria to produce peroxynitrite, which is a very potent oxidant. Peroxynitrite in turn induces oxidative stress, leading to hepatic cellular damage and necrosis [28,29].

Regarding to the hepatoprotective effects of M. pulegium extract, the results of present study indicated that, pre-administration of this extract for 8 consecutive days before subcutaneous injection of $\mathrm{CCl}_{4}$ protected hepatic cells from $\mathrm{CCl}_{4}$ induced damage. This was clear in histopathological findings of the examined liver of rabbits pre-treated with $M$. pulegium extract and subcutaneously injected with $\mathrm{CCl}_{4}$ (third and fourth groups), where the microscopic picture of the liver was greatly improved and only mild hepatic degenerative changes were observed particularly in liver of rabbits pretreated with $100 \mathrm{mg} M$. pulegium extract. The immunohistochemical studies confirmed the histopathological findings where iNOS and caspase 3 expression in the examined liver were significantly reduced in the third and fourth groups comparing with $\mathrm{CCl}_{4}$ group (fifth group). The hepatoprotective effect of M. pulegium could be attributed to its effectiveness in preventing lipid peroxidation $\left(\mathrm{EC}_{50}, 125 \pm 1.22\right)$ more than its ability to scavenge free radicals $\left(\mathrm{EC}_{50}, 1687.67 \pm 2.03\right)$. This opinion was supported by Jain et al., who recorded that pretreatment of ethanolic extract of $M$. pulegium significantly improved the glutathione, SOD, catalase, and peroxidase levels in rat intoxicated with $\mathrm{CCl}_{4}[24]$.

In the present study, the protective effect $M$. pulegium extract was likely to be dose dependent where $100 \mathrm{mg}$ of $M$ pulegium extract exerted more protection for hepatocytes against $\mathrm{CCl}_{4}$ induced hepatic damage than those of $50 \mathrm{mg}$ of $M$. pulegium extract. Therefore, further investigation for assessment of the hepatoprotective effect of larger doses of M. pulegium extract should be carried out to reach optimum dose with maximum protective effects of this extract.

Finally, results of current study suggested that M. pulegium had antioxidant and antiapoptotic properties that protect hepatocytes against acute hepatic damage and its protective effect was probably dose dependent.

\section{Acknowledgement}

This work was funded by Deanship of higher education and scientific research Aljouf University, Kingdom of Saudi Arabia, under grant no. (317/35). The authors, therefore, acknowledge with thanks to Deanship of higher education and scientific research Aljouf University for their financial support. 


\section{References}

1. Fashir B, Sivasubramaniam V, A Momen S, Assaf H (1996) Pattern of liver disease in a Saudi patient population: A decade of experience at security forces hospital, Riyadh, KSA. Saudi J Gastroenterol 2: 50-2. [Crossref]

2. Abdel-Moneim AS, Bamaga MS, Shehab GM, Abu-Elsaad AA, Farahat FM, et al. (2012) HCV infection among Saudi population: high prevalence of genotype 4 and increased viral clearance rate. PLoS One 7: e29781. [Crossref]

3. Abdo AA, Sanai FM, A-Faleh FZ (2012) Epidemiology of viral hepatitis in Saudi Arabia: are we off the hook? Saudi J Gastroenterol 18: 349-357. [Crossref]

4. Stickel F, Schuppan D (2007) Herbal medicine in the treatment of liver diseases. Dig Liver Dis 39: 293-304. [Crossref]

5. Silva BA, Ferreres F, Malva JO, Dias ACP (2005) Phytochemical and antioxidant characterization of Hypericum perforatum alcoholic extracts. Food Chem 90: 157-167.

6. Dorman HJ, KoÅŸar M, Kahlos K, Holm Y, Hiltunen R, et al. (2003) Antioxidant properties and composition of aqueous extracts from Mentha species, hybrids, varieties, and cultivars. J Agric Food Chem 51: 4563-4569. [Crossref]

7. Moreno L, Bello R, Primo-Yúfera E, Esplugues J (2002) Pharmacological properties of the methanol extract from Mentha suaveolens Ehrh. Phytother Res 16 Suppl 1: S1013. [Crossref]

8. Işcan G, Kirimer N, Kürkcüoğlu M, Başer KH, Demirci F, et al. (2002) Antimicrobial screening of Mentha piperita essential oils. J Agric Food Chem 50: 3943-3946. [Crossref]

9. Hajlaoui H, Trabelsi N, Noumi E, Snoussi M, Fallah H, et al. (2009) Biological activities of the essential oils and methanol extract of two cultivated mint species (Mentha longifolia and Mentha pulegium) used in the Tunisian folkloric medicine. World J Microbiol Biotechnol 25: 2227-2238 .

10. Yumuutas O, Saygideger SD (2012) Determination of antioxidant and antimutagenic activities of Phlomis armeniaca and Mentha pulegium. Journal of Applied Pharmaceutical Sciences 02: 36-40.

11. Delgado-Povedano MM, Luque de Castro MD (2013) Ultrasound-assisted analytical emulsification-extraction. Trends in Analytical Chemistry 45: 1-13.

12. Singleton VL, Rossi JA (1965) Colorimetry of total phenolics with phosphomolybdicphosphotungstic acid reagents. Amer J Enol Viticul 16: 144-158.

13. Eberhardt MV, Lee CY, Liu RH (2000) Antioxidant activity of fresh apples. Nature 405: 903-904. [Crossref]

14. Cheung LM, Cheung PCK, Ooi VEC (2003) Antioxidant activity and total phenolics of edible mushroom extracts. Food Chem 7: 249-255.

15. Patro BS, Rele S, Chintalwar GJ, Chattopadhyay S, Adhikari S, et al. (2002) Protective activities of some phenolic 1, 3- diketones against lipid peroxidation: possible involvement of the 1,3- diketone moiety. Chembiochem 3: 364-370. [Crossref]
16. Bancroft JD, Gamble M (2008) Theory and Practice of Histological Techniques. 6th Edition Churchill Livingstone Elsevier China: 93-120.

17. Laurentino SS, Correia S, Cavaco JE, Oliveira PF, Rato L, et al. (2011) Regucalcin is broadly expressed in male reproductive tissues and is a new androgen-target gene in mammalian testis. Reproduction 142: 447-456. [Crossref]

18. Morio LA, Chiu H, Sprowles KA, Zhou P, Heck DE, et al. (2001) Distinct roles of tumor necrosis factor-alpha and nitric oxide in acute liver injury induced by carbon tetrachloride in mice. Toxicol. Appl. Pharmacol 172: 44-51.

19. Mai TT, Fumie N, Chuyen NV (2009) Antioxidant activities and hypolipidemic effects of an aqueous extract from flower buds of Cleistocalyxoperculatus (Roxb.) merr. and perry. Biosci Biotechnol Biochem 33: 790-807. [Crossref]

20. Benabdallah A, Rahmoune C, Boumendjel M, Aissi O, Messaoud C, et al. (2016) Total phenolic content and antioxidant activity of six wild Mentha species (Lamiaceae) from northeast of Algeria. Asian Pacific Journal of Tropical Biomedicine 6: 760-766.

21. Sarikurkcu C, Eryigit F, Cengiz M, Tepe B, Cakir A, et al. (2012) Screening of the Antioxidant Activity of the Essential Oil and Methanol Extract of Mentha pulegium L. From Turkey. Spectroscopy Letters, 45: 352-358.

22. Bhattacharya H, Zhang S, Xiao Q (2008) Comparison of Histopathological Alterations Due to Sublethal CCl4 on Rosy Barb (Puntius conchonius) and Amphioxus (Branchiostoma belcheri) with Implications of Liver Ontogeny. Toxicology Mechanisms and Methods 18: 627-633.

23. Althnaian T, Albokhadaim I, E-Bahr SM (2013) Biochemical and histopathological study in rats intoxicated with carbon tetrachloride and treated with camel milk. Springerplus 2: 57. [Crossref]

24. Jain S, Jain DK, Balekar N (2012) In-Vivo Antioxidant activity of ethanolic extract of M. pulegium leaf against CC14 induced toxicity in rats. Asian Pacific Journal of Tropical Biomedicine S737-S740.

25. Weber LW, Boll M, Stampfl A (2003) Hepatotoxicity and mechanism of action of haloalkanes: carbon tetrachloride as a toxicological model. Crit Rev Toxicol 33: 105136. [Crossref]

26. Zhang B, Hirahashi J, Cullere X, Mayadas TN (2003) Elucidation of molecular events leading to neutrophil apoptosis following phagocytosis: cross-talk between caspase 8, reactive oxygen species, and MAPK/ERK activation. $J$ Biol Chem 278: 28443 [Crossref]

27. Guicciardi ME, Gores GJ (2005) Apoptosis: a mechanism of acute and chronic liver injury. Gut 54: 1024-1033. [Crossref]

28. Morio LA, Chiu H, Sprowles KA, Zhou P, Heck DE, et al. (2001) Distinct roles of tumor necrosis factor-alpha and nitric oxide in acute liver injury induced by carbon tetrachloride in mice. Toxicol Appl Pharmacol 172: 44-51. [Crossref]

29. Nussler AK, Billiar TR (1993) Inflammation, immunoregulation, and inducible nitric oxide synthase. J Leukoc Biol 54: 171-178. [crossref]

Copyright: $\odot 2017$ Osman IH. This is an open-access article distributed under the terms of the Creative Commons Attribution License, which permits unrestricted use, distribution, and reproduction in any medium, provided the original author and source are credited. 